\title{
ETNOZOOLOGI SEBAGAI PERTANDA OLEH MASYARAKAT DAYAK SIMPAKNG DI DESA MEKAR RAYA KECAMATAN SIMPANG DUA KABUPATEN KETAPANG
}

(Etnozoologi As a Sign By Dayak Simpakng Community In Mekar Raya Village Simpang Dua Subdistrict Ketapang Regency)

\author{
Yulius Yogi, M. Sofwan Anwari, S.M. Kartikawati \\ Fakultas Kehutanan, Universitas Tanjung Pura, Jalan Imam Bonjol Pontianak 78124 \\ Email: yogibahodanko@gmail.com
}

\begin{abstract}
Dayak Simpankg comunity in Mekar village are people who still hold the values inherited by their ancestors. One of the values that they are still running up to now is using animals as a sign. The purpose of this study is to find out the species of animal used as a sign, the part used and the meaning of the sign. The method used in field data collection is by interview and the data collection technique used is the snowball sampling method. Based on the results of the interview, 15 respondents were obtained. A total of 10 species animals from 10 families, namely Wild Pig, Clouded Leopard, Brown Wood Owl, White Rumped Munia, White Rumped Shama, Orange Bellied Flowerpecker, White Breasted Waterhen, Asian Paradise Flycatcher, Asian Toad and Flat Tailed Gecko are utilized by Dayak Simpakng comunity. Some parts that are used are sounds, animals that suddenly enter the house, and animals that pass above the head.
\end{abstract}

Keyword : Dayak Simpakng, Etnozoology, Pertanda

\section{PENDAHULUAN}

Pulau Kalimantan merupakan pulau urutan pertama dari lima pulau terluas yang ada di Indonesia. Keanekaragaman hayati yang tersebar di hutan Kalimantan sangat besar, maka Kalimantan memiliki kekayaan berupa keanekaragaman hayati baik tumbuhan maupun hewan. Hal ini dibuktikan oleh ilmuwan yang masih sering menemukan jenis-jenis baru baik hewan maupun tumbuhan. Sumber daya hayati seperti ini sangat berperan penting bagi kehidupan manusia. Menurut Suparlan (2005) dalam kehidupan manusia tidak lepas dari pemanfaatan sumber daya hayati berupa hewan dan tumbuhan.

Pemanfaatan hewan dan tumbuhan telah dilakukan oleh berbagai etnis yang ada di Kalimantan sejak dulu untuk memenuhi kebutuhan hidupnya, antara lain sebagai sumber bahan makanan, obatobatan, sarana ritual kebudayaan dan kepentingan ekonomi subsisten. Ragam pemanfaatan hewan merupakan implikasi dari beragamnya etnis, baik dalam hal jenis hewan yang dimanfaatkan, bentuk pemanfaatan maupun cara memanfaatkannya. Kegiatan manusia yang memanfaatkan secara berlebihan dapat berdampak kepada ketidakseimbangan ekosistem yang dapat merusak kekayaan alam itu sendiri sehingga dapat menjadi ancaman kepunahan jika tidak diawasi dengan baik..

Masyarakat pedalaman di Kalimantan yang hidup di dalam maupun diluar hutan 
masih menggantungkan hidupnya pada hutan yang ada di sekitar mereka. Keragaman dalam pemanfaatan hewan mendorong terbentuknya pola yaitu sebuah sistem atau cara kerja yang tetap dalam memanfaatkan berbagai jenis hewan. Hal ini berkaitan erat dengan proses interaksi yang berkembang antara etnis tertentu yang tinggal di sekitar hutan dengan alam lingkungannya dari waktu ke waktu. Interaksi yang kuat tersebut melahirkan cara tersendiri pada komunitas masyarakat dalam memperlakukan sumberdaya alamnya.

Salah satu etnis asli Provinsi Kalimantan Barat, yaitu suku Dayak Simpakng yang ada di Desa Mekar Raya Kecamatan Simpang Dua, Kabupaten Ketapang. Masyarakat Dayak Simpakng juga memiliki keragaman dalam pemanfaatan hewan baik untuk bahan pangan, obat-obatan, upacara adat dan supranatural dalam kehidupan sehari-hari.

Masyarakat suku Dayak Simpakng yang hidup secara berkelompok diketahui memanfaatkan berbagai jenis keanekaragaman hayati untuk kebutuhan hidup. Hubungan antara manusia dengan alam membentuk nilai-nilai yang arif dan menyatu dalam mengelola alam lingkungan. Informasi dan pengetahuan mengenai pemanfaatan hewan oleh suku Dayak Simpakng belum banyak diketahui, oleh sebab itu diperlukan kajian mengenai etnozoologi Masyarakat Dayak Simpakng Desa Mekar Raya, Kecamatan Simpang Dua, Kabupaten Ketapang.

Tujuan penelitian ini adalah 1) Mendata jenis-jenis hewan apa saja yang dimanfaatkan sebagai hewan pertanda oleh
Masyarakat Dayak Simpakng, Desa Mekar Raya, Kecamatan Simpang Dua, Kabupaten Ketapang 2). Mendata pemanfaatan hewan sebagai pertanda oleh Masyarakat Dayak Simpakng, Desa Mekar Raya, Kecamatan Simpang Dua, Kabupaten Ketapang.

\section{METODE}

Penelitian ini dilaksanakan di Desa Mekar Raya Kecamatan Simpang Dua Kabupaten Ketapang pada tanggal 15 April 2017 sd 30 April 2017 dengan menggunakan metode survey melalui wawancara mendalam (indept survey) terhadap responden terpilih. Pemilihan responden menggunakan teknik snow ball sampling atau dilakukan secara berantai dengan meminta informasi pada orang yang telah diwawancarai sebelumnya, demikian seterusnya (Poerwandari, 1998). Dengan dilakukan pencatatan mengenai keterangan jenis-jenis hewan yang dimanfaatkan masyarakat setempat (responden). Peneliti meminta rekomendasi calon responden dari kepala desa, kepala adat, kepala dusun, dukun, pengguna, orang tua, pemburu, dan lain lain.

Peneliti tidak membatasi jumlah responden maupun objek penelitian. Pengambilan data akan dihentikan apabila peneliti telah merasa data yang terkumpul telah cukup. Hal ini sesuai dengan konsep titik saturasi (saturation point) ketika data yang diperoleh tidak memberikan informasi baru dalam analisis (Parthami, 2009). Dalam penelitian ini telah diperoleh responden sebanyak 15 orang. Beberapa bagian yang dimanfaatkan sebagai pertanda adalah suara, hewan yang dengan 
tiba-tiba masuk ke dalam rumah, dan hewan yang melintas diatas atas kepala. Data yang didapat dari hasil wawancara dibuat dalam bentuk tabulasi kemudian dijabarkan secara deskriptif.

\section{HASIL DAN PEMBAHASAN}

Jenis Hewan yang Dimanfaatkan sebagai Pertanda oleh Mayarakat Dayak Simpankg

Berdasarkan dari hasil wawancara terdapat 10 jenis hewan yang dimanfaatkan oleh masyarakat Dayak Simpakng sebagai hewan pertanda, yang terdiri atas famili Suidae, Felidae, Strigidae, Estrildidae,
Muscicapidae, Cuculidae, Rallidae, Monarchidae, Bufonidae, Gekkonidae, yang termasuk kelas Mamalia, Aves, dan Amfibi. Kelas yang terbanyak dimanfaatkan sebagai hewan pertanda yaitu jenis Aves. Beragam jenis pemanfaatan yang digunakan sebagai pertanda yaitu dari suara, hewan yang tibatiba masuk ke dalam rumah, dan juga hewan yang terbang melintas di atas kepala manusia. Pemanfaatan hewan yang dipercayai oleh masyarakat Dayak Simpakng sebagai hewan pertanda disajikan pada tabel 1 .

Tabel 1. Pemanfaatan Hewan Sebagai Pertanda Oleh Masyarakat Dayak Simpakng di Desa Mekar Raya Kecamatan Simpang Dua Kabupaten Ketapang (The Use of Animals As A Sign By The Dayak Simpakng Community in Mekar Raya Village, Simpang Dua District, Ketapang Regency)

\begin{tabular}{|c|c|c|c|c|c|c|c|}
\hline \multirow{2}{*}{ No } & \multirow{2}{*}{ Nama Daerah } & \multirow{2}{*}{ Nama Indonesia } & \multirow{2}{*}{ Nama Ilmiah } & \multirow{2}{*}{ Pertanda- } & \multicolumn{3}{|c|}{ Status Perlindungan } \\
\hline & & & & & PP & CITES & IUCN \\
\hline \multicolumn{8}{|c|}{ Mamalia } \\
\hline 1 & Dori atau cis & Babi & Sus scrofa & $\checkmark$ & - & - & - \\
\hline 2 & Remaong & Macan Dahan & Neofelis nebulosa & $\checkmark$ & PP no7/1999 & I & VU \\
\hline \multicolumn{8}{|l|}{ Aves } \\
\hline 3 & Olang Kuap & Burung Hantu & Strix leptogrammica & $\checkmark$ & PP no7/1999 & - & $\mathrm{LC}$ \\
\hline 4 & Pipit & Burung Pipit & Lonchura striata & $\checkmark$ & PP no7/1999 & III & $\mathrm{LC}$ \\
\hline 5 & Gagurak & Burung Murai Batu & $\begin{array}{l}\text { Copsychus } \\
\text { malabaricus }\end{array}$ & $\checkmark$ & PP no7/1999 & - & NT \\
\hline 6 & Selaseh & Burung Kedasih & Cacomantis merulinus & $\checkmark$ & - & - & $\mathrm{LC}$ \\
\hline 7 & Keruak & Kareo Padi & $\begin{array}{l}\text { Amaurornis } \\
\text { phoenicurus }\end{array}$ & $\checkmark$ & - & - & - \\
\hline 8 & Burung Romak & Tali Mayat & Terpsiphone paradisi & $\checkmark$ & - & - & - \\
\hline \multicolumn{8}{|c|}{ Amfibi } \\
\hline 9 & Raong & Katak Batu & Bufo menalostictus & $\checkmark$ & - & - & - \\
\hline \multicolumn{8}{|l|}{ Reptil } \\
\hline 10 & Cocak & Cicak & Hemidactylus frenatus & $\checkmark$ & - & - & - \\
\hline
\end{tabular}


a. Dori (babi)

Dori adalah hewan peliharaan masyarakat Dayak Simpakng yang biasa berperan penting dalam kegiatan ritual. Seorang responden menjelaskan apabila seekor babi nonikng atau mengeluarkan suara dengan tidak seperti biasanya atau kedengarannya agak aneh disaat pagi itu menandakan hari akan mendung seharian.

b. Remaong (macan dahan)

Sebagian besar masyarakat Dayak Simpakng belum pernah melihat secara nyata hewan yang namanya remaong tetapi mereka percaya bahwa remaong adalah hewan jelmaan dari eyang buyut yang melindungi mereka. Mereka membuktikan remaong itu ada, dengan mendengar suara yang meraung saling bersahutan pada jam 12 malam dan pada waktu tertentu. Jika mendengar suara dengan tidak sengaja dipanggil lewat mantra dan sesajen berarti hewan tersebut memberi pertanda bahwa ada orang yang mau meninggal.

c. Olang kuap (burung hantu), pipit (burung pipit), gagurak (murai batu), keruak (kareo padi)

Keempat hewan ini memberi pertanda yang sama terhadap orang yang dituju. Masyarakat Dayak Simpakng mempercayai bahwa jika burung-burung itu masuk ke dalam rumah di malam hari melambangkan pertanda sesuatu yang buruk akan terjadi. Konon ceritanya hewan tersebut adalah titipan setan atau iblis yang mau mengganggu mereka. Guna menghindari agar sumpah itu tidak menjadi nyata maka mereka harus membunuh burung yang masuk, jika tidak terbunuh, mereka harus blit atau meningalkan rumah selama tiga hari. Rumah yang ditinggal harus disyarat oleh dukun menggunakan ayam satu ekor dan beras serta bacaan mantra dari sang dukun.

d. Selaseh (burung kedasih)

Burung ini berukuran kecil, namun memiliki suara yang lantang. Masyarakat Dayak Simpakng menyebutnya ini adalah burung jelmaan dari seseorang yang sudah meninggal. Mitosnya jika burung ini mengeluarkan suara itu pertanda menanyakan apa kabar, maka untuk orang yang mendengarnya harus menjawab layaknya seperti sebuah perumpamaan dan dengan sendirinya burung tersebut berhenti mengeluarkan suara.

e. Raong (katak batu)

Raong ini adalah hewan yang hidupnya di dua alam. Ciri-ciri kulitnya bagian belakang yang berbintil dan bersuara agak lantang membedakannya dengan kodokkodok yang lain. Masyarakat Dayak Simpakng mempercayai bahwa jika kodok ini bersuara tiap malam disungai sambil bersahutan dengan yang lain itu pertanda bahwa kampung halaman mereka terlindungi dari hantu samparan penebar penyakit yang misterius.

f. Burung Romak (Tali mayat) 
Burung tali mayat adalah burung yang dipercaya oleh masyarakat Dayak Simpakng sebagai burung kiriman Iblis. Burung romak yang terbang melintas di atas kepala dari arah kanan ke kiri berarti sedang memberi tanda yang tidak baik bagi orang yang mengalaminya. Salah satu cara agar hal tersebut tidak terjadi maka orang yang mengalaminya harus memberi isyarat dengan berjalan mundur sebanyak 7 langkah. Burung romak yang terbang dari arah kiri ke kanan berarti sedang memberi pertanda yang baik dan seseorang yang mengalaminya tidak perlu memberi isyarat.

g. Cocak (cicak)

Cicak adalah hewan rumahan yang semua orang mengetahui bentuk fisik dan suaranya. Masyarakat Dayak Simpakng mempercayai bahwa cicak adalah hewan kebenaran. Seseorang bercerita suatu kejadian di masa lalu disaat yang sama sang cicak juga mengeluarkan suara itu pertanda bahwa apa yang orang tersebut ceritakan berarti benar adanya.

Pola pemanfaatan hewan sebagai pertanda bersifat langsung tanpa adanya tindakan secara bertahap atau berkelanjutan karena memiliki nilai keberadaan.

\section{Ciri-ciri hewan yang dijadikan sebagai pertanda}

Ciri-ciri hewan yang dimanfaatkan oleh masyarakat Dayak Simpakng sebagai pertanda yang paling banyak adalah pada suara yaitu sebanyak 50\%, dari 10 jenis hewan yang dipercaya sebagai pertanda, terdapat 5 jenis hewan pemberi isyarat dengan mengeluarkan suara. Hewan-hewan tersebut antara lain: Babi, Macan Dahan, Burung Kedasih, Kodok Batu, dan Cicak. Hewan memberi pertanda dengan masuk kedalam rumah sebanyak $40 \%$, dari 10 jenis hewan yang dipercaya sebagai pertanda terdapat 4 jenis hewan pemberi isyarat dengan masuk kedalam rumah secara tidak sengaja. Hewan-hewan tersebut antara lain: Burung Hantu, Burung Pipit, Burung Murai Batu, dan Burung Kareo Padi. Hewan memberi pertanda saat terbang melintas diatas kepala sebanyak 10\%, dari 10 jenis hewan yang dipercaya sebagai pertanda terdapat 1 jenis hewan pemberi isyarat dengan terbang melintas diatas kepala. Hewan tersebut antara Lain: Burung Tali Mayat. Berikut ini tersaji diagram pemanfaatan hewan pertanda oleh Masyarakat Dayak Simpakng. 


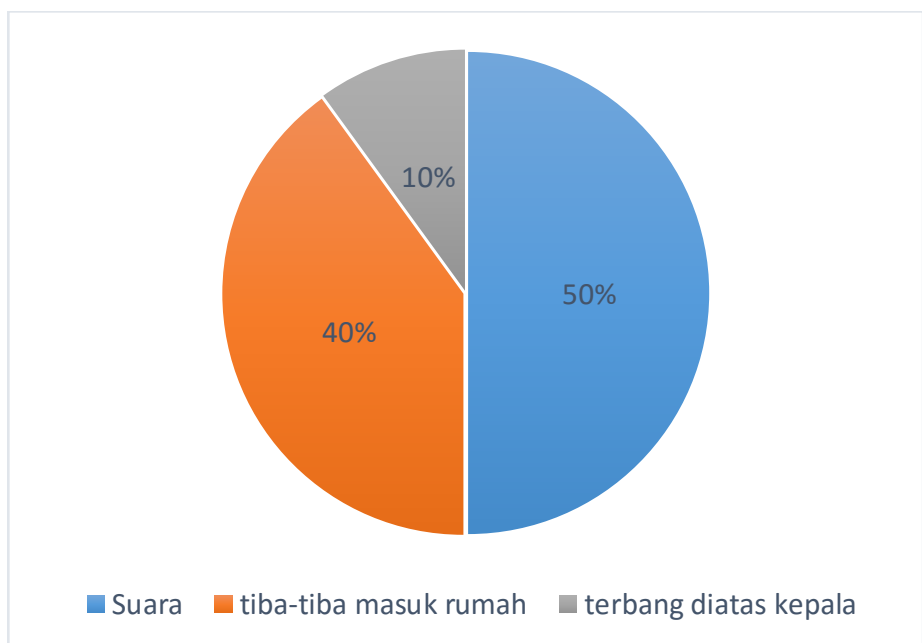

Gambar 1. Ciri-ciri hewan yang dijadikan sebagai Pertanda (Parts of Animals Used as Signs)

\section{Kesimpulan}

Masyarakat Dayak Simpakng sampai sekarang masih menjalankan kebiasaan atau tradisi adat dengan menggunakan hewan liar sebagai pertanda. Ciri-ciri hewan yang dimanfaatkan sebagai pertanda yaitu suara, tiba-tiba masuk rumah, dan terbang melintas diatas kepala manusia.

\section{Saran}

Perlunya dilakukan penelitian lebih lanjut mengenai etnozoologi agar memperoleh informasi yang lebih jelas tentang etnozoologi sebagai pertanda.

\section{UCAPAN TERIMAKASIH}

Terimakasih disampaikan kepada kedua orang tua dan para saudara yang selalu memberikan motivasi, sehingga penulis dapat menyelesaikan perkuliahan dan tidak lupa juga penulis mengucapkan terimakasih kepada dosen pembimbing dan dosen penguji yang dengan tidak lelah memberi masukan kepada penulis, demi melancarkan segala proses sehingga dapat berjalan dengan lancar dalam menyelesaikannya.

\section{DAFTAR PUSTAKA}

Alves.2012.https://www.researchgate.ne t/profile/Romulo_Alves2/publicati on/268631584_Relationship_betw een fauna and people and the $r$ ole_of_ethnozoology_in_animal conservation/links/5558a8fd08ae9 80ca61055c0.pdf Diakses pada tanggal 10 september 2017

Dewin, L. V., Anwari, S., dan Prayogo, H. 2017. Kajian Etnozoologi Masyarakat Dayak Seberuang Di Desa Gurung Mali Kecamatan Tempunak Kabupaten Sintang. Jurnal Hutan Lestari, Vol. 5 (4): $978-986$

Eprilurahman, R. I. K, Kusmana dan S.D. Yudha. 2012. Sekilas Etnozoologi Masyarakat Dayak Di Kalimantan. Fakultas Biologi Universitas Gadjah Mada

Parthami, P.W. 2009. Kontruksi Identitas Jender. Universitas Indonesia: Jakarta. 
Poerwandari, E. K. 1998. Metode Penelitian Sosial.Universitas Terbuka: Jakarta

Riwut, N. 2010. Hewan Pertanda. http://www.nilairiwut.com/id/budaya/dahiaang-or Petanda?start $=1$ Diakses pada tanggal 10 september 2017

Suparlan P. 2005. Suku Bangsa dan Hubungan antara Suku Bangsa
Cetakan Kedua Yayasan Pengembangan Kajian Ilmu Kepolisian Perss, Jakarta.

Wollenberg, E., A. Uluk., dan M. Sudana. 2001. Ketergantungan Masyarakat Dayak Terhadap Hutan di Sekitar Taman Nasional Kayan Mentarang. Bogor :CIFOR. 